\title{
Auger electron spectroscopy study of semiconductor surfaces: Effect of cleaning in inert atmosphere
}

Jolien Debehets, Sérgio M. C. Miranda, Pía Homm, Michel Houssa, Marc Seefeldt, Jean-Pierre Locquet, and Jin Won Seo

Citation: Journal of Vacuum Science \& Technology B, Nanotechnology and Microelectronics: Materials, Processing, Measurement, and Phenomena 34, 041227 (2016);

View online: https://doi.org/10.1116/1.4955149

View Table of Contents: http://avs.scitation.org/toc/jvb/34/4

Published by the American Vacuum Society

\section{Articles you may be interested in}

Effect of porosity and pore size on dielectric constant of organosilicate based low-k films: An analytical approach Journal of Vacuum Science \& Technology B, Nanotechnology and Microelectronics: Materials, Processing, Measurement, and Phenomena 34, 041205 (2016); 10.1116/1.4946838

X-ray diffraction analysis for step and linearly graded $\ln _{x} \mathrm{Ga}_{1-\mathrm{X}} \mathrm{As} / \mathrm{GaAs}(001)$ heterostructures using various hkl reflections

Journal of Vacuum Science \& Technology B, Nanotechnology and Microelectronics: Materials, Processing, Measurement, and Phenomena 34, 041209 (2016); 10.1116/1.4949517

Tilted ion implantation as a cost-efficient sublithographic patterning technique Journal of Vacuum Science \& Technology B, Nanotechnology and Microelectronics: Materials, Processing, Measurement, and Phenomena 34, 040608 (2016); 10.1116/1.4953085

Surface analysis and cathodoluminescence degradation of undoped $\mathrm{ZnO}$ and $\mathrm{ZnO}: \mathrm{Zn}$ phosphors Journal of Vacuum Science \& Technology B, Nanotechnology and Microelectronics: Materials, Processing, Measurement, and Phenomena 34, 041221 (2016); 10.1116/1.4953561

Toward synthesis of oxide films on graphene with sputtering based processes Journal of Vacuum Science \& Technology B, Nanotechnology and Microelectronics: Materials, Processing, Measurement, and Phenomena 34, 040605 (2016); 10.1116/1.4949565

Deep traps and instabilities in AIGaN/GaN high electron mobility transistors on Si substrates Journal of Vacuum Science \& Technology B, Nanotechnology and Microelectronics: Materials, Processing, Measurement, and Phenomena 34, 041216 (2016); 10.1116/1.4953347

Contact Hiden Analytical for further details: w www.HidenAnalytical.com E info@hiden.co.uk CLICK TO VIEW our product catalogue

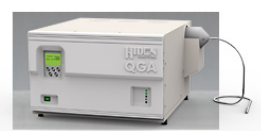

Gas Analysis dynamic measurement of reaction gas streams catalysis and thermal analysis molecular beam studies dissolved species probes , fermentation

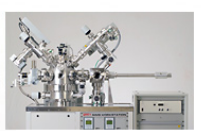

Surface Science

UHVTPD

SIMS

end point detection in ion beam etch elemental imaging - surface mapping

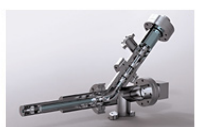

Plasma Diagnostics

plasma source characterization etch and deposition process reaction kinetic studies analysis of neutral and radical species

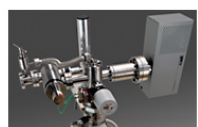

Vacuum Analysis partial pressure measurement and control of process gases reactive sputter process control vacuum diagnostics vacuum coating process monitoring 


\title{
Auger electron spectroscopy study of semiconductor surfaces: Effect of cleaning in inert atmosphere
}

\author{
Jolien Debehets ${ }^{a)}$ \\ Department of Materials Engineering, KU Leuven, Kasteelpark Arenberg 44 box 2450, 3001 Heverlee, \\ Belgium \\ Sérgio M. C. Miranda, Pía Homm, and Michel Houssa \\ Department of Physics and Astronomy, KU Leuven, Celestijnenlaan 200D, 3001 Heverlee, Belgium \\ Marc Seefeldt \\ Department of Materials Engineering, KU Leuven, Kasteelpark Arenberg 44 box 2450, 3001 Heverlee, \\ Belgium \\ Jean-Pierre Locquet \\ Department of Physics and Astronomy, KU Leuven, Celestijnenlaan 200D, 3001 Heverlee, Belgium \\ Jin Won Seo \\ Department of Materials Engineering, KU Leuven, Kasteelpark Arenberg 44 box 2450, 3001 Heverlee, \\ Belgium
}

(Received 23 March 2016; accepted 17 June 2016; published 1 July 2016)

In this paper, the authors demonstrate that Auger electron spectroscopy (AES) is an effective characterization tool in the analysis of the cleaning of semiconductor surfaces under different atmospheres. AES has several advantages for this purpose: it is nondestructive, surface specific \{the analysis depth is only 4-50 $\AA$ [Childs et al., Handbook of Auger Electron Spectroscopy (Physical Electronics, Eden Prairie, MN, 1995)]\}, and very sensitive to common contaminants such as carbon and oxygen. Furthermore, the authors have proven that AES allows us to describe the effectiveness of surface cleaning in a quantitative manner by comparing the peak-to-peak height of the oxygen signal for different samples. In this work, the surface cleaning of five semiconductors, namely, $\mathrm{Si}$, Ge, GaAs, $\mathrm{In}_{0.5} \mathrm{Ga}_{0.5} \mathrm{As}$, and $\mathrm{In}_{0.5} \mathrm{Al}_{0.5} \mathrm{As}$, was investigated. The same standard $\mathrm{HF}$ cleaning procedure was applied in two different atmospheres, air or nitrogen. The latter was used to prevent reoxidation after cleaning. The authors found that for most of these semiconductors, the atmosphere in which the cleaning is performed has a significant influence on the results, reducing the oxygen peak-to-peak height with an extra $11.18 \%$ (average of all the semiconductors investigated) when comparing cleaning in $\mathrm{N}_{2}$ to cleaning in air. Complementary characterization of the effectiveness of the cleaning procedure was accomplished by in situ AES, atomic force microscopy, and reflection high-energy electron diffraction for GaAs samples. (C) 2016 American Vacuum Society.

[http://dx.doi.org/10.1116/1.4955149]

\section{INTRODUCTION}

The removal of native oxides on semiconductor surfaces is a crucial processing step in the transistor industry: for silicon and germanium, it is preferred to remove the native oxide before the deposition of a high-k oxide in order to decrease leakage through the gate stack. For III-V semiconductors, native oxides cause Fermi-level pinning, 2,3 and therefore, a proper cleaning is crucial for the usage of these materials in transistor applications, as suggested by the ITRS roadmap. 4

An excellent tool to investigate the surface cleaning is Auger electron spectroscopy (AES). The Auger electron transition and a schematic of the experimental setup are shown in Fig. 1. An Auger electron is generated in three steps: (1) a vacancy is created by the removal of a core electron [red in Fig. 1(a)] through the incoming electron beam (blue). (2) A second electron (purple) drops down to fill the

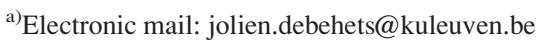

vacant position, which (3) generates enough energy to eject an electron in a shell with higher energy, the Auger electron, indicated in green. The AES setup is illustrated in Fig. 1(b). The Auger electrons enters between the inner hemisphere (IH) and outer hemisphere $(\mathrm{OH})$, between which a voltage is applied as to only allow electrons within a small range of energies to reach the detector. ${ }^{5}$ By varying the voltage applied on the hemispheres, electrons with different energies are detected as to obtain a full spectrum.

AES has often been used to identify which elements are present at the surface, sometimes combined with sputtering to obtain a depth profile of these elements. However, in this paper, it is shown that AES can also be used to evaluate the effectiveness of different cleaning procedures in a quantitative manner without relying on data obtained from reference samples. Typically, a quantitative analysis with AES is done using sensitivity factors, often extracted from databases. However, the measurements to obtain these sensitivity factors are performed on different instruments and on different materials than the material under investigation. 
a)

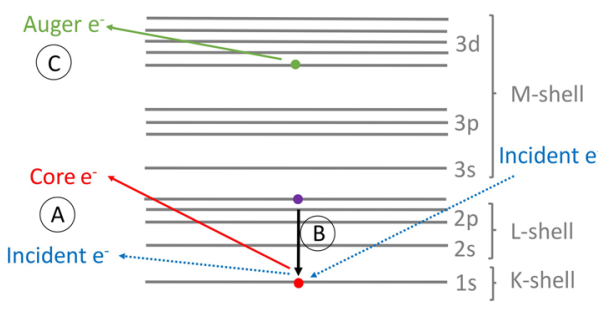

b)

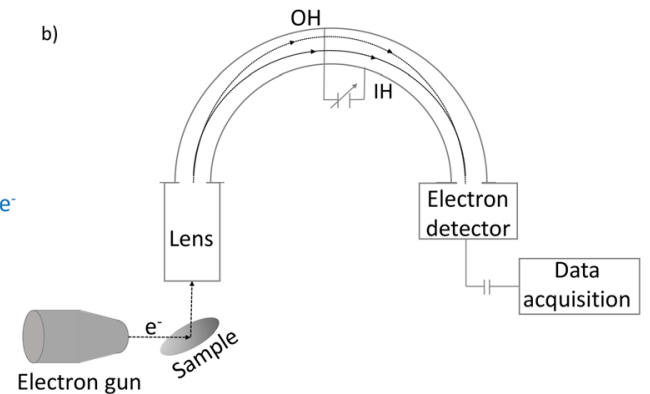

Electron gun

FIG. 1. (Color online) (a) Schematic illustration of the generation of an Auger electron. An incident electron creates a vacant position by removing a core electron. Next a transition takes place where an electron from a higher shell fills the vacant spot, generating enough energy to eject the Auger electron. (b) Schematic of the AES setup, where electrons with a specific energy are selected in a hemispherical detector by applying a voltage between the inner (IH) and outer hemisphere (OH). After A. R. Barron (Ref. 5).

Consequently, this quantitative analysis based on references samples is not highly accurate and may lead to an error between $14 \%$ and $20 \%$ in atomic percentage. ${ }^{6}$ In this paper, we show that AES can be used to evaluate the relative effectiveness of different cleaning procedures in a quantitative manner without relying on sensitivity factors obtained from reference samples. The quantitative analysis described in this paper is based on the peak-to-peak height comparison of specific elements for different but similar samples, as the peak-topeak height in the differentiated spectrum is directly proportional to the amount of that element present. This quantitative method does not rely on measurements performed on other materials and with other setups and therefore has a high precision. The error introduced by noise can be estimated accurately for each measurement and is typically below $10 \%$. It should be noted that the surface composition of the sample is not obtained in atomic percentages with this method, but a relative decrease or increase in a specific element from one sample to another is obtained in terms of percentages.

AES allows investigating both, the peaks related to the contaminants, and those related to the semiconductor species. The large signal strength in AES for carbon and oxygen makes it possible to directly assess cleaning effects. It is not necessary to assess low concentrations of contaminants indirectly by looking at the peaks related to the semiconductor constituents as can be required for XPS. The cause of this difference between AES and XPS is differences in signal strengths and surface sensitivity due to electron path lengths. ${ }^{1}$ Like XPS, AES can be used to detect changes in the chemical state of elements. In both techniques, peak shifts and a peak shape change can occur. However, for AES, it is more difficult to relate the peak shift to the electronic configuration change as the peaks are broader than in the case of XPS. Furthermore, there are more databases available for XPS to investigate chemical state changes. However, significant peak shape changes can be observed in AES for peaks involving valence band electrons, as is shown in Fig. 2(b). AES, on the other hand, is preferred when examining individual small particles as the spatial resolution of this technique is better than for XPS. Disadvantages of AES include beam damage due to heating and bond breaking for some materials, and challenges examining insulating materials due to charging effects. Although charging can occur in both AES and XPS, methods for charge control are easier and more routine for XPS. For the materials considered here, no charging effects were observed.

\section{EXPERIMENT}

In this work, the effectiveness of the cleaning of five different semiconductors was systematically investigated by means of AES. The semiconductors studied are from group IV ( $\mathrm{Si}, \mathrm{Ge}$ ) and III-V compounds (GaAs, $\mathrm{In}_{0.5} \mathrm{Ga}_{0.5} \mathrm{As}$ and $\left.\mathrm{In}_{0.5} \mathrm{Al}_{0.5} \mathrm{As}\right)$. The $\mathrm{Si}, \mathrm{Ge}$, and GaAs wafers were all (100)oriented and n-type. The doping varied from $4.8 \times 10^{15}$ for $\mathrm{Si}, 4.7 \times 10^{16}$ for $\mathrm{GaAs}$, to $1.2 \times 10^{16}$ for Ge. Both, ternary $\mathrm{In}_{0.5} \mathrm{Ga}_{0.5} \mathrm{As}$ and $\mathrm{In}_{0.5} \mathrm{Al}_{0.5} \mathrm{As}$ semiconductor layers, are grown lattice matched on an InP (001)-oriented substrates by metal organic vapor phase epitaxy using the experimental setup described in Merckling et al. ${ }^{7}$ The thickness of both layers is $150 \mathrm{~nm}$, as extracted from the Pendellösung fringes periodicity by $\mathrm{x}$-ray diffraction. For each sample, an asreceived piece was used as a reference and two cleaning procedures were applied. Cleaning procedure 1 consisted of standard HF cleaning where a sample was dipped into a $0.5 \% \mathrm{HF}$ solution for $2 \mathrm{~min}$. Subsequently, the remaining HF was removed from the surface with dust free paper. This effectively removed the HF from the surface, as no residual fluor was detected in the subsequent AES measurements. Cleaning procedure 2 was identical, except that the whole procedure was conducted in a nitrogen environment instead of air. To be precise, the cleaning was performed in a portable glove box (Erlab Captair Pyramid), which was evacuated and purged at least three times with ultrapure $(99.8 \%) \mathrm{N}_{2}$ gas to minimize the amount of contaminants present in the glove box. In this at best $99.8 \%$ pure $\mathrm{N}_{2}$ atmosphere, the sample was cleaned with $\mathrm{HF}$ and then enclosed in a specifically designed container to be transported to the vacuum system for characterization. To avoid direct exposure to air, also the loading of the sample to the vacuum system was done in nitrogen atmosphere using a second glove bag filled with $\mathrm{N}_{2}$.

The AES equipment (Thermofisher, Alpha 110 Channeltron Assembly) (the sample geometry and system layout is shown in Fig. 1) was used yielding an electron voltage of $8 \mathrm{kV}$ and a filament current of $2 \mathrm{~A}$. The pressure in the chamber was $4 \times 10^{-9}$ mbar. The step size for data collection was $1 \mathrm{eV}$, and the spot size is estimated to be $1 \mathrm{~mm}^{2}$. Differentiation was 


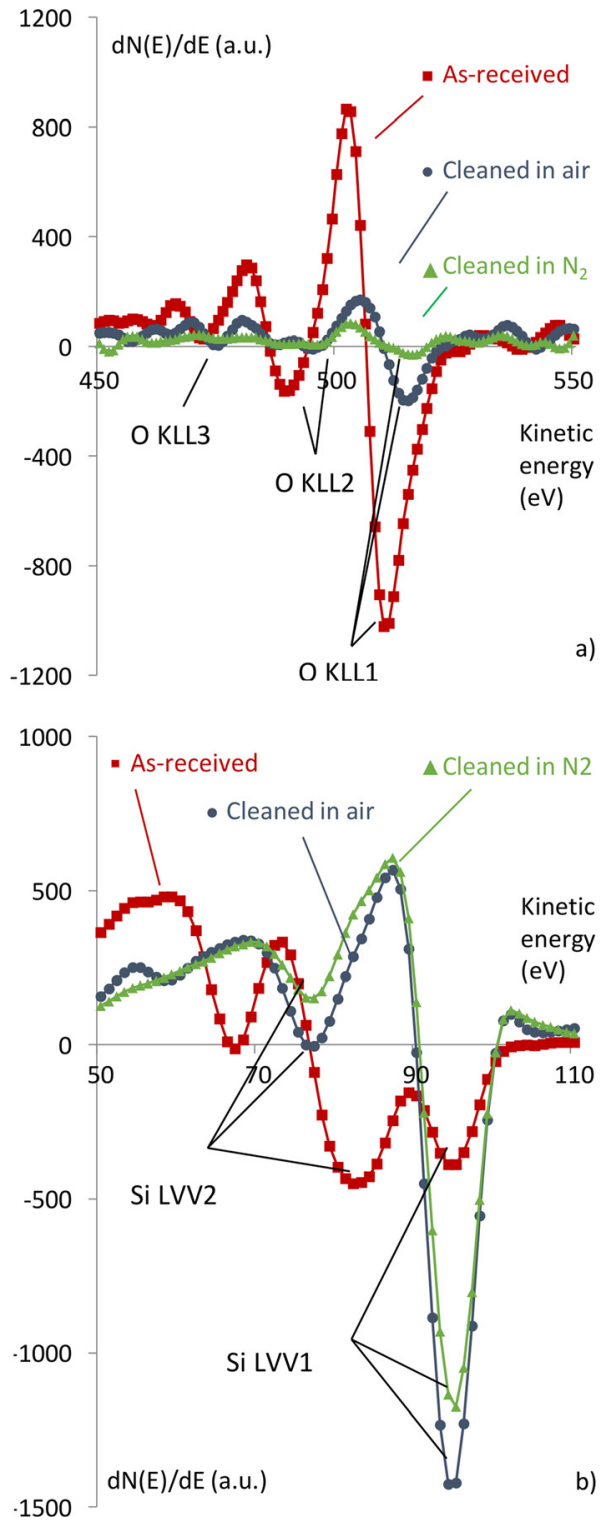

FIG. 2. (Color online) Differentiated AES spectra showing (a) the oxygen KLL peaks for three different $\mathrm{Si}$ samples (as-received, cleaned with HF $0.5 \% 2^{\prime}$ in air or in a nitrogen atmosphere). A significant decrease in peakto-peak height upon cleaning is observed. (b) Same samples as in (a) showing a distinct shape change of the Si LVV peaks (related to a transition involving valence electrons).

applied to the spectra using the AVANTAGE 3.13 software (differentiation width of $7 \mathrm{eV}$ and seven data points per differentiation) in order to filter out the influence of the background. Before differentiation, a smoothening procedure was conducted (Savitzky and Golay, cubic function). The software was also applied to obtain a quantitative analysis of the composition of the surface, where the atomic fraction of the elements present on the surface was estimated based on the use of sensitivity factors. As discussed in the Introduction, this type of analysis may have a low accuracy. However, peaks were identified (they may be positioned slightly differently compared to the database), and the standard software was applied to obtain an estimate of the surface composition.

A simple and precise method to assess the relative effectiveness of different cleaning procedures that does not rely on instrumental sensitivity factors is used in this study. In this method, the peak-to-peak height of contaminant elements is compared using the differentiated spectrum. This method assumes that the elements of interest are at the sample surface and the reliability of this method requires that measurements on samples cleaned in different ways are conducted under nearly identical conditions. Especially the filament current (and therefore the intensity of the background in the as measured curve) is an important factor in this process. The reproducibility of this method was confirmed by repeating experiments on GaAs and $\mathrm{Si}$ several times under similar conditions (not included in this paper). Furthermore, this method can only be applied to peaks where no significant peak shape changes occur.

\section{RESULTS AND DISCUSSION}

\section{A. Characterization by AES}

The differentiated peak for the oxygen KLL (referring to the shells from which the electrons originate that are involved in the transition) transitions in silicon is shown in Fig. 2(a), for an as-received, cleaned in air and cleaned in nitrogen atmosphere wafer. As it can be seen, the peak-to-peak height of the oxygen KLL1 peak decreases significantly upon cleaning, indicating that the cleaning process efficiently removes oxygen bonded to the surface. The KLL2 and KLL3 peaks are barely visible after cleaning. In the case of the silicon wafer cleaned in nitrogen, all oxygen peaks are hardly distinguished from the background.

Besides the peak height, the peaks originating from transitions involving the valence band electrons of the semiconductor also changed their shape upon cleaning, as illustrated in Fig. 2(b) for the silicon samples. This shape change is directly related to the density of states of the valence band ${ }^{1}$ and the change in our investigation is similar to that observed in the literature. ${ }^{8,9}$ This shape change is significantly pronounced for the Si LVV2 (where L corresponds to the L-shell and V to valence band) peak: upon cleaning the minimum of this peak is shifted to lower kinetic energies and the peak height increases, while the maximum between Si LVV1 and Si LVV2 increases drastically. Taking into account that the native oxide thickness of an as-received silicon can be up to $2 \mathrm{~nm},{ }^{10-12}$ these results demonstrate that AES spectroscopy is an effective tool to study the influence of the cleaning on the surface composition as well as the density of states.

The same two cleaning procedures were also applied to $\mathrm{Ge}, \mathrm{GaAs}, \mathrm{In}_{0.5} \mathrm{Ga}_{0.5} \mathrm{As}$, and $\mathrm{In}_{0.5} \mathrm{Al}_{0.5}$ As wafers. The peakto-peak height for oxygen is presented in Fig. 3 for each semiconductor for the as-received, cleaned in air, and cleaned in $\mathrm{N}_{2}$ samples. The spectra were shifted vertically for clarity. The symbols represent the measured values for each cleaning whereas the gray lines indicate the margin given by the $5 \%$ confidence interval for $\pm 2 \sigma$, which means that $95 \%$ of the measurements fall within this margin when random distribution due to noise is taken into account. The standard noise deviation was estimated for each measurement from a $150 \mathrm{eV}$ window where no Auger transitions are 


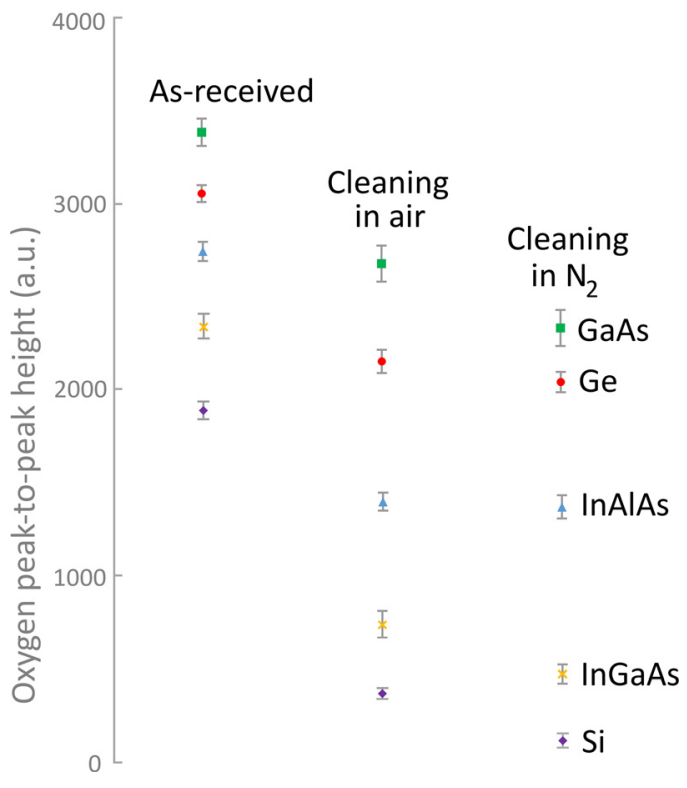

FIG. 3. (Color online) Peak-to-peak height of the oxygen transition as measured by AES for the as-received semiconductors and after the cleaning procedures. The symbols indicate the oxygen (KLL) peak-to-peak height, and the gray lines represent the $\pm 2 \sigma$ intervals which estimate the interval which contain $95 \%$ of the measurements as to account for noise. The position of the spectra is shifted vertically for clarity.

present. Table I shows the decrease in oxygen peak-to-peak height in relative percentages. For most semiconductors investigated in this study, the HF cleaning is very effective, leading to a significant decrease in the oxygen peak-to-peak height up to $93 \%$. Especially in a nitrogen atmosphere, the effect was strongly pronounced. $\mathrm{In}_{0.5} \mathrm{Al}_{0.5} \mathrm{As}$ is the only material for which no significant difference in oxygen peakto-peak height was observed when comparing cleaning in both atmospheres.

It should be noted that the samples cleaned in air were only exposed to air for a few minutes before loading into the vacuum system. This shows that most of these semiconductors rapidly absorb contaminants from the atmospheric environment after cleaning. For GaAs, we performed cleaning in air and then exposed the samples to air for different durations before inserting them into the vacuum system for the AES measurements (see Fig. 4). When the sample is immediately inserted in the vacuum system, it is only a few minutes in contact with air after HF cleaning and before insertion in the load lock (it takes approximately 15 min to pump down to $1.5 \times 10^{-6}$ Torr). If the sample is left in air for $30 \mathrm{~min}$, no

TABLE I. Decrease in oxygen peak-to-peak height upon cleaning in terms of percentages.

\begin{tabular}{lcc}
\hline \hline & $\begin{array}{c}\text { As-received-cleaned } \\
\text { in air }(\%)\end{array}$ & $\begin{array}{c}\text { As-received-cleaned } \\
\text { in } \mathrm{N}_{2}(\%)\end{array}$ \\
\hline $\mathrm{GaAs}$ & $45.8 \pm 5.1$ & $68.1 \pm 4.7$ \\
$\mathrm{Ge}$ & $54.7 \pm 3.6$ & $61.2 \pm 3.3$ \\
$\mathrm{In}_{0.5} \mathrm{Al}_{0.5} \mathrm{As}$ & $73.1 \pm 2.7$ & $74.7 \pm 3.4$ \\
$\mathrm{In}_{0.5} \mathrm{Ga}_{0.5} \mathrm{As}$ & $73.1 \pm 3.3$ & $85.3 \pm 2.3$ \\
$\mathrm{Si}$ & $80.6 \pm 1.5$ & $93.9 \pm 1.9$ \\
\hline \hline
\end{tabular}

significant difference in the oxygen peak-to-peak height could be detected compared to the sample inserted in the vacuum chamber immediately. However, within the first hour in air and beyond, the sample reoxidizes until the oxygen peakto-peak height stabilizes to a value similar to an as-received wafer.

The speed of reoxidation after cleaning mainly depends on the structure of the formed oxide layer, as a layer of partially oxidized semiconductor is expected to be defective and therefore permeable, promoting diffusion of oxygen into the subsurface area. ${ }^{13}$ The oxides formed on GaAs are generally known to be highly defective suboxides, ${ }^{14,15}$ which is consistent with the cleaning in nitrogen being significantly more efficient than the cleaning in air. For the other semiconductors studied, the native oxides are less defective compared to $\mathrm{GaAs},{ }^{16-20}$ resulting in a less pronounced, but still significant, difference between the samples cleaned in air and those cleaned in $\mathrm{N}_{2}$. For $\operatorname{In}_{0.5} \mathrm{Al}_{0.5} \mathrm{As}$ the situation is different, since aluminum is strongly susceptible to oxidation and the reoxidation of $\operatorname{In}_{0.5} \mathrm{Al}_{0.5} \mathrm{As}$ in an inert atmosphere has been reported before. ${ }^{21}$ This can be caused by small amounts of residual oxygen present in the nitrogen atmosphere $(99.8 \%$ pure) or oxygen in the HF-solution itself. However, it is expected that this oxide formed at the $\mathrm{In}_{0.5} \mathrm{Al}_{0.5} \mathrm{As}$ interface is more stable against progressive oxidation than that of the other semiconductors studied here, since $\mathrm{Al}_{2} \mathrm{O}_{3}$ is widely used in the aluminum industry as a barrier for further oxidation. ${ }^{22}$ The formation of such an oxide layer during cleaning, even in a nitrogen atmosphere, explains why the results of the cleaning in air and in nitrogen are comparable.

In the case of GaAs, the surface stoichiometry can be estimated based on the Auger peak-to-peak height, as Ga and As undergo the same LMM transitions and these peaks are relatively close in kinetic energy. Furthermore, the inelastic mean free path is similar, therefore the yield of Auger electrons is comparable. ${ }^{23}$ From the differentiated spectrum, it was derived that the $\mathrm{Ga}$ /As ratio varies from 1.33 in the asreceived wafer to 0.97 and 0.94 for the GaAs cleaned in air and $\mathrm{N}_{2}$, respectively. Marchiori et al. ${ }^{24}$ reported the Ga/As ratio before and after cleaning with $\mathrm{HF}$ solution and found similar results by means of XPS. The decrease in Ga/As ratio upon cleaning with $\mathrm{HF}$, or the relative increase in the yield of Auger electrons from As, is also in agreement with other reports. ${ }^{24-27}$ A possible explanation for the decrease in $\mathrm{Ga} /$ As ratio is the preferential removal of Ga-oxide species, resulting in a $\mathrm{Ga}$ depleted surface covered by elemental arsenic. $^{21,24,28,29}$ However, a layer of elemental arsenic was mostly observed when a high concentration of $\mathrm{HF}$ was applied, ${ }^{29}$ and in our case, the $\mathrm{Ga} / \mathrm{As}$ ratio is rather close to unity after cleaning in $\mathrm{N}_{2}$; therefore, no large deviations in stoichiometry are expected.

The atomic percentage of elements present at the surface was also estimated by using sensitivity factors supplied by the manufacturer (see Table II). It has to be noted that this type of analysis may lead to an error between $14 \%$ and $20 \%$ in atomic percentage. $^{6}$ This error is introduced because the reference samples from which the sensitivity factors are determined are 


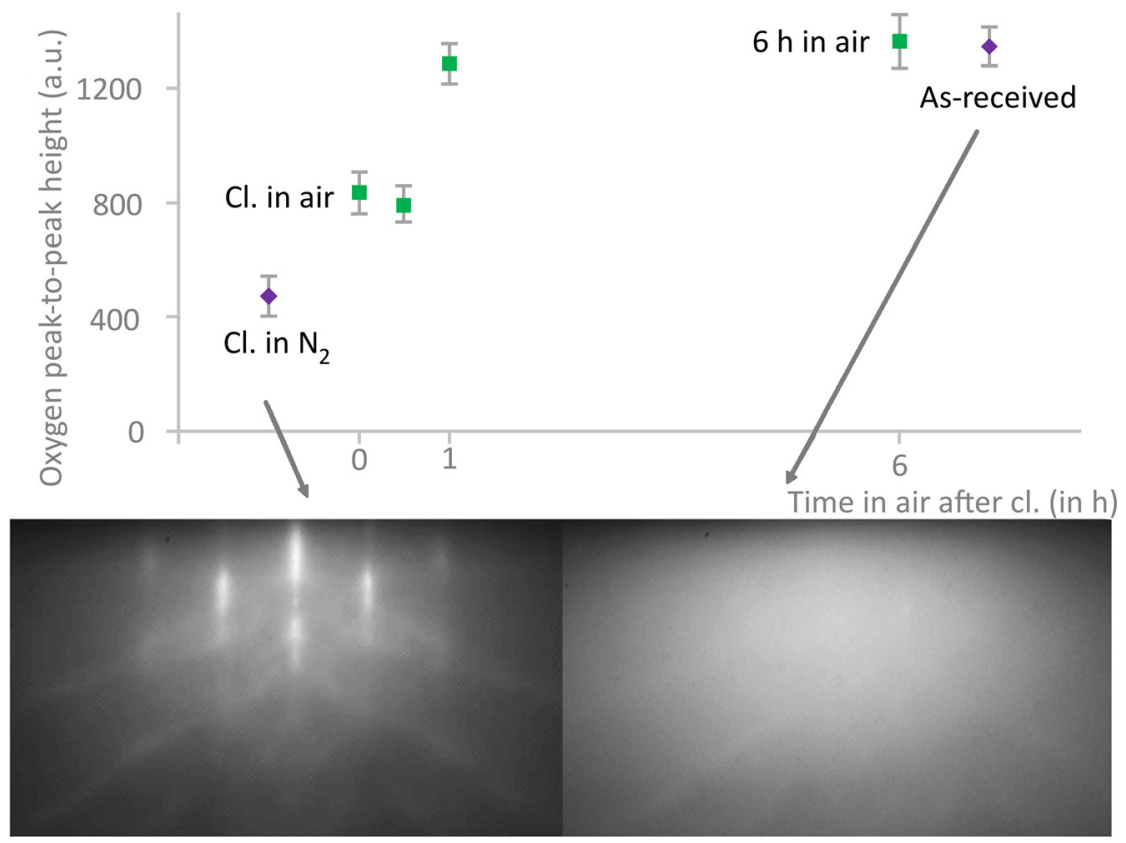

FIG. 4. (Color online) Upper part: oxygen peak-to-peak height for GaAs samples as a function of exposure time to air before insertion in vacuum. Lower part: RHEED patterns along the [011] azimuth of a GaAs (100) wafer cleaned in a $\mathrm{N}_{2}$ environment (left) and an as-received wafer (right). Both images have the same contrast and brightness.

actually measured in another equipment and may therefore deviate from the real values. Furthermore, the inelastic mean free path of the measured species may differ from that of the reference samples, which can contribute to the error.

It should also be mentioned that the interpretation of the results for $\mathrm{In}_{0.5} \mathrm{Ga}_{0.5} \mathrm{As}$ and $\mathrm{In}_{0.5} \mathrm{Al}_{0.5} \mathrm{As}$ can be affected by partial overlapping of the In and C signals. For $\mathrm{In}_{0.5} \mathrm{Al}_{0.5} \mathrm{As}$, a quantitative approach is even more complicated because the aluminum peaks have a very low intensity, indicating either a high oxygen coverage or a low amount of aluminum in the original surface region. It has been reported that the amount of $\mathrm{Al}$-oxides on the as-received $\mathrm{In}_{0.5} \mathrm{Al}_{0.5} \mathrm{As}$ can be disproportionally high, compared to the amount of

TABLE II. Composition of the surface according to the AES analysis based on sensitivity factors. All quantities are atomic percentages.

\begin{tabular}{|c|c|c|c|c|c|c|c|c|c|}
\hline & & $\mathrm{Si}$ & $\mathrm{Ge}$ & $\mathrm{Ga}$ & As & In & $\mathrm{Al}$ & $\mathrm{O}$ & $\mathrm{C}$ \\
\hline \multirow[t]{3}{*}{$\mathrm{Si}$} & No Cl. & 67.6 & I & I & I & I & / & 27.3 & 5.1 \\
\hline & $\mathrm{Cl}$. in air & 87.7 & / & / & / & I & / & 9.0 & 3.3 \\
\hline & $\mathrm{Cl}$. in $\mathrm{N}_{2}$ & 94.4 & / & I & I & I & I & 2.3 & 3.3 \\
\hline \multirow[t]{3}{*}{$\mathrm{Ge}$} & No Cl. & I & 80.7 & I & / & I & / & 14.8 & 4.5 \\
\hline & $\mathrm{Cl}$. in air & I & 92.9 & I & I & I & / & 4.4 & 2.7 \\
\hline & $\mathrm{Cl}$. in $\mathrm{N}_{2}$ & I & 94.4 & / & I & I & / & 3.8 & 1.8 \\
\hline \multirow[t]{3}{*}{ GaAs } & No Cl. & I & / & 46.0 & 41.6 & I & I & 7.8 & 4.6 \\
\hline & $\mathrm{Cl}$. in air & / & / & 42.8 & 48.9 & I & / & 5.3 & 3.0 \\
\hline & Cl. in $\mathrm{N}_{2}$ & I & / & 43.1 & 50.6 & / & / & 4.2 & 2.1 \\
\hline \multirow{3}{*}{$\mathrm{In}_{0.5} \mathrm{Ga}_{0.5} \mathrm{As}$} & No Cl. & I & / & 17.6 & 33.5 & 19.0 & I & 23.1 & 6.8 \\
\hline & $\mathrm{Cl}$. in air & I & I & 18.4 & 48.2 & 28.4 & / & 3.4 & 1.7 \\
\hline & Cl. in $\mathrm{N}_{2}$ & / & I & 26.7 & 56.8 & 13.7 & / & 1.7 & 1.1 \\
\hline \multirow[t]{3}{*}{$\mathrm{In}_{0.5} \mathrm{Al}_{0.5} \mathrm{As}$} & No Cl. & I & / & I & 44.8 & 30.8 & 4.2 & 15.3 & 5.0 \\
\hline & Cl. in air & I & I & I & 64.4 & 23.5 & 5.7 & 5.4 & 1.9 \\
\hline & $\mathrm{Cl}$. in $\mathrm{N}_{2}$ & I & I & I & 50.9 & 37.5 & 4.6 & 2.1 & 4.9 \\
\hline
\end{tabular}

In/As-oxides, because $\mathrm{Al}$ is much more susceptible to oxidation than In or As. ${ }^{21}$

\section{B. Characterization by RHEED and AFM}

Complementary characterization of the effectiveness of the cleaning procedure was obtained by performing atomic force microscopy (AFM) in the noncontact mode and reflection high-energy electron diffraction (RHEED) on a GaAs sample. Both techniques were applied in UHV $\left(10^{-8} \mathrm{mbar}\right.$ for RHEED, $10^{-9}$ for $\mathrm{AFM}$ ) at room temperature. The observed RHEED patterns from a wafer cleaned in $\mathrm{N}_{2}$ and from an as-received wafer are shown in Fig. 4. As RHEED uses electrons at grazing incidence, just the first atomic layers from the surface are sensed. Clear diffraction streaks and Kikuchi lines are observed on the cleaned sample, whereas for the as-received wafer the strikes are hardly visible due to the presence of the amorphous native oxide. The diffraction features in the RHEED pattern suggest that the cleaning has significantly reduced the thickness of the native oxide layer and the wafer surface is smooth. ${ }^{30,31}$ From the AFM measurements, similar root mean square roughness's were found for a polished, as-received wafer $(0.19 \mathrm{~nm})$ and a wafer cleaned in a $\mathrm{N}_{2}$ atmosphere $(0.16 \mathrm{~nm})$, showing that the cleaning preserves the lower roughness of the surface. The RHEED image shows no reconstruction of the surface, which normally only appears after annealing at higher temperature. ${ }^{14}$

\section{SUMMARY AND CONCLUSIONS}

In summary, the use of Auger electron spectroscopy to analyze the $\mathrm{HF}$ cleaning of $\mathrm{Si}, \mathrm{Ge}, \mathrm{GaAs}, \mathrm{In}_{0.5} \mathrm{Ga}_{0.5} \mathrm{As}$, and $\mathrm{In}_{0.5} \mathrm{Al}_{0.5} \mathrm{As}$ semiconductors in air or in nitrogen environment 
was investigated. By comparing the peak-to-peak height of oxygen for the different samples, the effectiveness of the cleaning was analyzed quantitatively. For all the studied semiconductors, except $\operatorname{In}_{0.5} \mathrm{Al}_{0.5} \mathrm{As}$, the cleaning in a nitrogen environment proved to be significantly more efficient than the cleaning in air. For silicon, a distinctive change of the peak shape related to a change in chemical environment was observed. Furthermore, the composition of the samples was estimated based on the systematic analysis performed. AFM and RHEED characterization on GaAs samples showed evidence of the cleaning procedure effectiveness.

\section{ACKNOWLEDGMENTS}

This work was funded by Ph.D. fellowship of the Fund of Scientific Research-Flanders (FWO-V) (Dossier No. 11U4514N). P.H. acknowledges support from Becas ChileCONICYT. It was also supported by the Belgian Hercules Stichting with the Project No. HER/08/25 and AKUL/13/19, the FWO Odysseus Program and the KU Leuven Project GOA "Fundamental challenges in Semiconductor Research." The authors gratefully acknowledge Marc Heyns and Clement Merckling for providing the InGaAs/InP and InAlAs/InP heterostructures. The authors would also like to thank Bastiaan Opperdoes and Ludwig Hendrickx for technical support.

${ }^{1}$ K. D. Childs, B. A. Carlson, L. A. LaVanier, J. F. Moulder, D. F. Paul, W. F. Stickle, D. G. Watson, and C. L. Hedberg, Handbook of Auger Electron Spectroscopy (Physical Electronics, Eden Prairie, MN, 1995).

${ }^{2}$ Y. Hwang, R. Engel-Herbert, N. G. Rudawski, and S. Stemmer, J. Appl. Phys. 108, 034111 (2010).

${ }^{3}$ M. Caymax et al., Microelectron. Eng. 86, 1529 (2009).

${ }^{4}$ See "Process integration, devices and structures," in International Technology Roadmap of Semiconductors 2013 Edition, http://www.itrs.net/home.html.

${ }^{5}$ A. R. Barron, Physical Methods in Chemistry and Nano Science (Connexions, Rice University, Houston, TX, 2012).
${ }^{6}$ C. J. Powell and M. P. Seah, J. Vac Sci. Technol., A 8, 735 (1990).

${ }^{7}$ C. Merckling et al., J. Appl. Phys. 115, 023710 (2014).

${ }^{8}$ B. A. Joyce and J. H. Neave, Surf. Sci. 27, 499 (1971).

${ }^{9}$ E. G. Keim, Surf. Sci. 148, L641 (1984).

${ }^{10}$ X. Fan, H. Liu, B. Zhong, C. Fei, X. Wang, and Q. Wang, Appl. Phys. A 119, 957 (2015).

${ }^{11}$ K. W. Schroder, A. G. Dylla, S. J. Harris, L. J. Webb, and K. J. Stevenson, ACS Appl. Mater. Interfaces 6, 21510 (2014).

${ }^{12}$ J. H. Mazur, R. Gronsky, and J. Washburn, Microscopy of Semiconducting Materials Conference, Oxford, 21-23 March (1983), p. 77.

${ }^{13}$ E. L. Cussler, Diffusion Mass Transfer in Fluid Systems, 3rd ed. (Cambridge University, Cambridge, United Kingdom, 2009).

${ }^{14} \mathrm{~S}$. Oktyabrsky and P. D. Ye, Fundamentals of III-V Semiconductor MOSFETS (Springer, London, 2010).

${ }^{15}$ P. D. Ye, J. Vac. Sci. Technol., A 26, 697 (2008).

${ }^{16}$ M. Scarrozza, G. Pourtois, M. Houssa, M. Caymax, A. Stesmans, M. Meuris, and M. M. Heyns, Microelectron. Eng. 86, 1747 (2009).

${ }^{17}$ J. Robertson, Eur. Phys. J. Appl. Phys. 28, 265 (2004).

${ }^{18}$ G. D. Wilk, R. M. Wallace, and J. M. Anthony, J. Appl. Phys. 89, 5243 (2001).

${ }^{19}$ A. Toriumi, T. Tabata, C. H. Lee, T. Nishimura, K. Kita, and K. Negashio, Microelectron. Eng. 86, 1571 (2009).

${ }^{20}$ A. Dimoulas et al., Thin Solid Films 515, 6337 (2007).

${ }^{21}$ Y. Sun, P. Pianetta, P.-T. Chen, M. Kobayashi, Y. Nishi, N. Goel, M. Garner, and W. Tsai, Appl. Phys. Let. 93, 194103 (2008).

${ }^{22}$ C. Vargel, Corrosion of Aluminium (Elsevier, Amsterdam, 2004).

${ }^{23}$ S. Valeri, M. Lolli, and P. Sberveglieri, Surf. Sci. 238, 63 (1990).

${ }^{24}$ C. Marchiori, D. J. Webb, C. Rossel, M. Richter, M. Sousa, C. Geri, R. Germann, C. Andersson, and J. Fompeyrine, J. Appl. Phys. 106, 114112 (2009).

${ }^{25}$ M. Akazawa and H. Hasegawa, Appl. Surf. Sci 256, 5708 (2010).

${ }^{26}$ A. Chanda, S. Verma, and C. Jacob, Bull. Mater. Sci. 30, 561 (2007).

${ }^{27}$ F. L. Lie, W. Rachmady, and A. J. Muscat, Microelectron. Eng. 87, 1656 (2010).

${ }^{28}$ N. J. Smeenk, J. Engel, P. Mulder, G. J. Bauhuis, G. M. M. W. Bissels, J. J. Schermer, E. Vlieg, and J. J. Kelly, ECS J. Solid State Sci. Technol. 2, P58 (2013).

${ }^{29}$ S. Adachi and D. Kikuchi, J. Electrochem. Soc. 147, 4618 (2000).

${ }^{30}$ F. Tang, T. Parker, G.-C. Wang, and T.-M. Lu, J. Phys. D: Appl. Phys. 40, R427 (2007).

${ }^{31}$ O. P. Karpenko, S. M. Yalisove, and D. J. Eaglesham, J. Appl. Phys. 82, 1157 (1997). 